\title{
Unintentional and efficient relational priming
}

\author{
Vencislav Popov • Penka Hristova
}

Published online: 10 March 2015

(C) Psychonomic Society, Inc. 2015

\begin{abstract}
If relational priming is responsible for unintentional analogical reasoning, as has been suggested, it too should occur unintentionally. However, results from previous studies are inconclusive - studies that use the sensicality task usually demonstrate unintentional priming, while lexical decision tasks have failed to capture the effect without explicitly instructing participants to note and use the relational similarity in the stimuli. We discuss possible reasons for these contradictory results. Based on this discussion, we aimed to maximize our chances to find an effect by ensuring that the primes and targets elicit the same processing, by using a longer SOA, suitable for the more complex nature of the task, and by ensuring that the stimuli are good exemplars of the relations that hold between them. We present two experiments that obtained unintentional and efficient priming of relations with a lexical decision task. Participants made a lexical decision for a target pair of words more quickly when it was preceded by a similarly related pair of words, compared to an unrelated pair. Participants were not instructed to note and use the relations. Experiment 2 extended those results by showing that the effect is present even when executive working memory resources are occupied by a secondary task. Even though it turned out that the base pairs differed on semantic similarity, co-occurrence and imageability between the two conditions, these differences were not responsible for the effect. Thus, relations can be primed unintentionally and efficiently, even when relational integration is not necessitated by task demands.
\end{abstract}

\footnotetext{
V. Popov $(\triangle) \cdot$ P. Hristova

Department of Cognitive Science and Psychology, New Bulgarian

University, Sofia, Bulgaria

e-mail: vencislav.popov@gmail.com

P. Hristova

e-mail: phristova@cogs.nbu.com
}

Keywords Relational priming - Lexical decision task · Relational reasoning $\cdot$ Relational similarity $\cdot$ Relational processing $\cdot$ Priming of relations

Life constantly faces us with novel situations, people, objects or problems, which we must comprehend and deal with. Such comprehension is necessarily based on previously stored knowledge, and one way to cope with that novelty is to use analogies - to identify situations in memory that share consistent relational similarities with the situation at hand and to make inferences based on those shared similarities (Gentner \& Smith, 2012). This process can be fully deliberate and its product subject to awareness - faced with novel information we may intentionally search for stored knowledge to help us to understand it in terms of something already known. Thus, analogy can be seen as the result of complex, intentional and computationally expensive cognitive processes (Holyoak, 2012). Alternatively, analogical reasoning can also be spontaneous and unintentional, as Hofstadter has argued via many convincing examples in categorization, perception, and language (Hofstadter, 1979, 1984, 2001; Hofstadter \& Sander, 2013).

Indeed, several studies demonstrate that previously encountered analogs can spontaneously influence online interpretation of complex cases such as beliefs about marihuana prohibition (Blanchette \& Dunbar, 2002), attitudes toward gay people (Perrott, Gentner, \& Bodenhausen, 2005), text comprehension (Day \& Gentner, 2007), and thematic role assignment in ambiguous sentences (Popov \& Hristova, 2014). Spontaneous transfer of relational information can also improve problem solving in some cases (Day \& Goldstone, 2011; Dixon \& Dohn, 2003). There is also evidence that analogies can be not only unintentional but unconscious as well 
(Day \& Gentner, 2007; Day \& Goldstone, 2011; Popov \& Hristova, 2014).

On the other hand, it seems that analogical reasoning requires executive resources - performing a secondary task that requires working memory resources increases similaritybased responses at the cost of relational ones (Waltz, Lau, Grewal, \& Holyoak, 2000). The same is true when inducing anxiety in participants (Tohill \& Holyoak, 2000; although, see Hristova, Petkova, \& Kokinov, 2013, and Hristova \& Kokinov, 2011, for an opposite result) which, according to attentional control theory, reduces task efficiency because worry thoughts occupy working memory, and participants become more susceptible to distraction (Eysenck, Derakshan, Santos, \& Calvo, 2007). For that reason, Holyoak (2012) has argued that the unintentional transfer in the implicit analogy literature is unlikely to result from a systematic mapping of the relational structure. According to him, a "more piecemeal" transfer occurs based only on the activation and priming of key relational concepts, and no systematic mapping is developed between the analog and the target. Thus, the candidate mechanism he identifies to explain the implicit analogy results is relational or analogical priming. ${ }^{1}$

Relational priming occurs when a target word pair (PLANET-CORE; is in the center of) is comprehended more quickly or easily after a relationally similar base pair (FRUITPIT; is in the center of), compared to a relationally dissimilar base pair (STAGE-PIT; Bassok, Pedigo, \& Oskarsson, 2008; Estes, 2003; Estes \& Jones, 2006; Gagné, 2001; Hristova, 2009b; Raffray, Pickering, \& Branigan, 2007; Spellman, Holyoak, \& Morrison, 2001; Wisniewski \& Love, 1998 ). If priming of key relations is responsible for the results in the implicit analogy literature, as Holyoak (2012) has argued, it should also be able to occur unintentionally, efficiently or without awareness (Bargh, 1994; Moors \& De Houwer, 2006). However, the evidence for unintentional relational priming is mixed.

Spellman et al. (2001) reported that relational priming occurs only when participants are given explicit instructions that focus their attention on the relational similarity between the word pairs. Their participants did a double lexical decision task in which they had to respond to whether two letter strings presented simultaneously are both words or not. Without explicit instructions for attending to the relations, lexical decisions were not faster for target pairs (BEAR CAVE) on trials in which the base and target pairs of words shared a similar relation (BIRD CAGE). There was no effect even after instructing participants to attend to the relations because they would be on a later memory test. The only significant facilitation $(25 \mathrm{~ms})$ appeared after they told participants that the

\footnotetext{
${ }^{1}$ The two terms have been used interchangeably in the literature. For consistency, in the rest of the paper we will refer to the effect as "relational priming" or "priming of relations."
}

second pair of words might be related in the same way as the first two words are, and that they should pay attention to the relations because they might help them in identifying the words. Based on those results, they concluded that relational priming is an intentional process, and that it requires attentional modulation.

Other studies have reported that relational priming occurs even without giving explicit instructions to note and use the common relations. Gagné (2001) used a sensicality task in which participants had to decide whether two words make sense as a phrase. A noun-noun compound (STUDENT VOTE) was comprehended more easily when it was preceded by a relationally similar compound (STUDENT ACCU SATION), compared to a relationally dissimilar one (STUDENT CAR), but only when the modifier was repeated across both phrases. Later, she found that it is not necessary to repeat the modifier but that there must be high lexical similarity between the two modifiers - SCHOLAR ACCUSATION facilitates STUDENT VOTE, because SCHOLAR and STUDENT are lexically related (Gagné, 2002). In fact, even lexical similarity is not necessary - the key issue seems to be the degree of relational similarity across the word pairs (Estes, 2003; Estes \& Jones, 2006).

Estes and Jones (2006) argued that Gagné (2001, 2002) failed to obtain relational priming with lexically dissimilar items because the relational similarity in her stimuli was too low, and because it was virtually identical in the related and unrelated conditions. Relational similarity predicted reaction times in a regression analysis even though there was no overall difference between the groups, and lexical similarity was not a significant predictor. A further experiment in which they controlled both factors showed that the comprehension of noun-noun compounds based on a composition relation (COTTON SOCKS) is facilitated after processing a relationally similar but lexically dissimilar word pair (SILVER BELL), compared to after processing a relationally dissimilar word pair (SILVER MINE). Thus, only specific relations (SOCKS made of COTTON, BELL made of SILVER) can be primed, not general ones (SOCKS of COTTON, MINE of SILVER), which were the ones used by Gagné (also, see Bendig \& Holyoak, 2009). Unfortunately, Estes and Jones (2006) used only instances of the composition relation, which might have made it very salient, and it casts some doubt on whether the effect was truly unintentional.

Interestingly, relational priming occurs unintentionally even in a task in which it is detrimental to performance (Hristova, 2009b). Hristova presented participants with word pairs in sequence that either shared a similar relation or not. One word in each pair changed its color $1,000 \mathrm{~ms}$ after it appeared on screen, and the change in the base and the target was either congruous (black-to-blue in both pairs) or incongruous (black-to-blue in the base and black-to-green in the target). The relational similarity between the base and target 
pairs interacted with the color change type - incongruous color judgments for the target were slower and congruous judgments were faster when the pairs were relationally similar, compared to when they were dissimilar.

Relational priming was also reported in an explicit analogy verification task, where participants were prompted to name the color of the shared relation after judging whether two word pairs were analogically related (Green, Fugelsang, \& Dunbar, 2006). Finally, semantic relations can even prime arithmetic operations such as addition (Bassok et al., 2008), and misalignment of semantic and arithmetic relations produces a P600 ERP effect, demonstrating that relational integration is attempted unintentionally even across distinct knowledge domains (Fisher, Bassok, \& Osterhout, 2010).

We can think of four broad reasons for the discrepancy between Spellman et al.'s (2001) failure to obtain unintentional relational priming and Estes and Jones' (2006) success. One possibility is to attribute it to the lexical nature of Spellman et al.'s (2001) task. While the sensibility task requires the participant to integrate two concepts into a sensible whole and in that way to recognize, at least implicitly, the relation that holds between them, this is not required in the lexical decision task, in which relations are irrelevant. In essence, the sensibility task necessitates a relational judgment while the lexical decision and naming tasks do not (Holyoak, 2012). It may be that relations are activated and used in subsequent processing only when this is required by the nature of the task being executed. This is the way both Estes and Jones (2006) and Holyoak (2012) explain the pattern of mixed results, although this explanation cannot account for Hristova's (2009b) results.

This explanation is also contradicted by data from the integrative priming paradigm, which demonstrates that words unintentionally and efficiently activate the relations that hold between them, even in lexical decision tasks. Similar to semantic and associative priming, integrative priming is evident when it is easier to process a single word after processing a related word (Estes \& Jones, 2009). However, in integrative priming, the prime and the target are neither associated nor semantically similar, but they can be integrated into a meaningful phrase. For example, lexical decisions for the target WINE are faster after the prime BOX, with which it can be meaningfully integrated, than after both unrelated primes (COPPER), and after a baseline (******; Estes \& Jones, 2009). It appears that word pairs automatically activate the relations that hold between their constituents, and the system uses those relations to integrate them, whether or not this is necessitated by the task (Estes \& Jones, 2009; Mather, Estes \& Jones, 2014).

Another reason for the lack of effect in Spellman et al. (2001) might be that the base and target pairs were processed differently - while participants had to decide if the target contains words, they only had to read the base while expecting a later memory test. Dixon and Dohn (2003) show that for spontaneous transfer to occur, participants have to actively engage with the processing of the base structure in the same way they do with the target. Indeed, in all cases that demonstrate either implicit analogical reasoning or relational priming, the base and the target situations were processed similarly, whether it be just reading, problem solving, or cognitive decision making (Blanchette \& Dunbar, 2002; Day \& Gentner, 2007; Day \& Goldstone, 2011; Dixon \& Dohn, 2003; Estes \& Jones, 2006; Gagné, 2001, 2002; Hristova, 2009b; Popov \& Hristova, 2014).

Third, a longer stimulus onset asynchrony (SOA) may be required for relational priming to occur. Spellman et al. (2001) used an SOA of $400 \mathrm{~ms}$, which most associative and semantic priming studies consider to be the upper time limit for an indicator of uncontrolled processing (Neely, 1991; Jones \& Estes, 2012). However, in those paradigms the prime is a single word, and activation may spread to its associates immediately after it has been recognized, while in the relational priming paradigm the prime is a pair of words, both of which must be recognized and relationally integrated before activation spreads to other instances of that relation. If no time is allotted for the relation that holds between them to be activated, it is not possible for it to be primed (Hristova, 2009a). With a color-judgment task, Hristova (2009a) systematically manipulated the interval between the base and the target (100/ $400 / 700 \mathrm{~ms}$ ), and discovered that relational priming occurred only when the target appeared $700 \mathrm{~ms}$ after a judgment was made on the base pair. In fact, both Gagné $(2001,2002)$ and Estes and Jones (2006) used SOAs longer than that - Gagné's studies were self-paced with an SOA around $1,100 \mathrm{~ms}$ for the sensicality decision on the base plus another self-determined interstimulus interval, Estes's (2003) SOA was more than 2, $000 \mathrm{~ms}$, and the Estes and Jones's (2006) SOA was around 2, $350 \mathrm{~ms}$.

Finally, to detect a relational priming effect, which is usually small, it may be necessary to more carefully control the relational similarity between base and target pairs. As Estes and Jones (2006) argued, Gagné (2001) failed to obtain relational priming in one experiment because the relational similarity turned out to be equivalent in the high and low similarity conditions. Also, Spellman et al. (2001) reasoned that if relational priming exists and is unintentional, then it is probably the result of spreading activation from the activated instance of the relational concept to all other instances of it, and then to the word pairs that could successfully fill the roles required by that relation. Yet, any number of pairs of concepts can share the same relation, and there is no reason to suppose that it will activate all of its instances equally well. Just as single concepts can differ in their typicality of the superordinate category, and that affects reaction times in lexical decision and naming tasks (Neely, 1991), word pairs can differ in how good of an exemplar they are of a relation, and that 
difference affects processing time as well (Chaffin \& Herrmann, 1984, 1988).

Thus, it remains an open question whether and under what conditions relational priming can occur unintentionally. If it does underlie results from the implicit analogical reasoning paradigm, as Holyoak (2012) has suggested, the cognitive system should be able not only to automatically activate relations that hold between activated concepts (integrative priming), but to unintentionally and efficiently use these relations in further processing (relational priming).

Since results from previous studies are inconclusive, our main goal in this paper was to demonstrate that relational priming can occur even with a lexical decision task. To that end we attempted to maximize our chances to find an effect by ensuring that the primes and targets elicit the same processing, by using a longer SOA, suitable for the more complex nature of the task, and by ensuring that the stimuli are good exemplars of the relations that hold between them. Importantly, we did not manipulate those factors systematically, and follow-up studies should explore what combination of them is necessary for the effect to appear.

We present two experiments that demonstrate successful relational priming with a lexical decision task, in which, contrary to Spellman et al. (2001), participants were not instructed that there was any connection between the base and target pairs, and which used a variety of relations, contrary to Estes and Jones (2006). Experiment 2 shows that the effect is present even when executive working memory resources are heavily taxed by a secondary task (generation of random intervals; Vandierendonck, De Vooght, \& Van der Goten, 1998).

\section{Experiment 1}

We tested whether there would be a facilitation in a lexical decision task (LDT), if the target pair of words (PLANETCORE) is preceded by a relationally similar pair (FRUIT-PIT; Same Relation condition), compared to trials in which it is preceded by a relationally dissimilar pair (STAGE-PIT; Different Relation condition), while controlling word pairs for semantic similarity and global co-occurrence, and individual words for written frequency, length, and orthographic neighborhood size to discard alternative explanations.

\section{Method}

\section{Participants}

Thirty-eight undergraduates (16 males) at New Bulgarian University participated for partial fulfillment of course credit or for free. Their mother tongue was Bulgarian, and their age ranged from 18 to 35 years $(M=22.05, S D=3.38)$.

\section{Materials}

A single trial consisted of two word pairs that either shared a similar relation or not. The final set of experimental stimuli included 24 such trials ( 48 word pairs). Reaction times in an LDT are affected by many variables (association strength, length, frequency, category dominance, orthographic neighborhood, etc.; Neely, 1991), and because there is no readily available data for words in Bulgarian, our stimuli underwent a number of pretests and controls, detailed below. We initially took 41 proportional verbal analogies of the type $A: B:: C: D$ in Bulgarian from the pool of items used in Hristova (2009b), and we generated an additional set of 102 analogies (a total of 143 analogies).

Unambiguousness of the analogy Since many verbal analogies of the type A:B::C:? can be completed equally well by different concepts (STAIRS:MARBLE::RING:? can be completed with GOLD, SILVER, PLATINUM, etc.), we wanted to use only analogies in which the D term can be determined unambiguously, so that the target pair will be a typical instance of the relation in the base. A separate sample of participants ( $N$ $=84$ ) accessed an online survey tool (http://esurv.org/), in which they saw incomplete forms of all 143 analogies (A:B::C:?) in randomized order, and they had to generate the fourth term of the analogy. They had to type the first answer they can think of that will complete the analogy. ${ }^{2}$ Sixty of the analogies were given the same dominant answer by more than $80 \%$ of participants, and they were selected for the second pretest stage.

Similarity In order to control for the possible confound of semantic priming, similarity was estimated with the construct of feature overlap (Mather et al., 2014). We created pairs for comparison by combining the four terms of each of the 60 analogies selected from the previous phase, which resulted in six pairs per analogy and 360 pairs in total. A separate sample of participant $(N=111)$ judged the feature similarity of each of the 360 pairs on a scale from 1 (not at all similar) to 7 (completely similar) via an online survey tool (http://esurv. org/). As in the previous study, participants were instructed to submit even partial completion of the procedure. Since the task was tedious, administered online, and its completion took a long time, there was a risk that some participants might answer randomly. We developed a procedure to determine which answers might be the result of random input. For each participant we calculated the variance of

\footnotetext{
${ }^{2}$ We urged them to complete the whole set, but we asked them to submit even partial responses if they decided to quit. This was done in order to increase the number of valid responses, and the randomized order guaranteed that partial completions would be spread evenly among stimuli. Of the participants, $82.14 \%$ gave an answer to each of the 143 analogies. The remaining participants answered on average $66.6 \%$ of the stimuli $(S D=$ $35 \%)$.
} 
their answers from the whole sample of participants by calculating the average value of the squared deviations of their responses on each item from the average response on each item. The mean variance of 100 cases of randomly generated responses was $5.71(S D=0.32)$, and all participants whose variance was larger than this were removed from the sample $(N=16)$. We received pairwise similarity ratings for each pair of terms within an analogy (A:B, A:C, A:D, B:C, B:D, C:D). Results were taken into account in matching the final stimuli into groups.

Global relative co-occurrence Association strength affects priming (Neely, 1991), but because there is no readily available data for association strength in Bulgarian, we used a novel co-occurrence measure as a substitute for association strength (lexical co-occurrence correlates highly with association strength; Spence \& Owens, 1990). Absolute frequency of co-occurrence of two words within a window of text is an inadequate measure for this purpose because it will be strongly affected by the frequency of the words themselves - strongly associated words that are themselves infrequent would be infrequently met together, and weakly associated but independently frequent words may result in artificially high absolute co-occurrence. We estimated the relative forward frequency of co-occurrence (RFFC) which conceptually is the conditional probability that WORD2 will appear within 20 words after WORD1, and it is calculated with formula (1), where $f(w 1$, $w 2)$ is the absolute co-occurrence frequency of WORD1 and WORD2 in that order, and $f(w 1)$ is the frequency of WORD1:

$P_{20}(w 2 \mid w 1)=\frac{f(w 1, w 2)}{f(w 1)}$

The relative backwards frequency of co-occurrence (RBFC) would depend on the frequency of WORD2. ${ }^{3}$

$P_{-20}(w 1 \mid w 2)=\frac{f(w 1, w 2)}{f(w 2)}$

RFFC was calculated for all pairs within a set. The frequencies were derived from the Bulgarian National Corpus, a database of over 240000 Bulgarian text samples amounting to 1.2 billion words (Koeva, Stoyanova, Leseva, Dimitrova, Dekova, \& Tarpomanova, 2012).

\footnotetext{
${ }^{3}$ Thus, the calculations conceptually reflect both general association, and also the distinction between forward and backward association strength. For example, the RFFC and the RBFC for the word pair SHIP:HARBOUR are 0.03 and $0.19-$ SHIP is associated with a much larger array of concepts compared to HARBOUR, and its forward association strength with it is weaker than the backward association strength from HARBOUR to SHIP.
}

Final set of experimental stimuli Trials for the Different Relation condition were created by changing the first term of the analogy with a word matched on length, orthographic neighborhood size, and frequency with the original word, and matched on co-occurrence and semantic similarity with the target. For example, the word SCHOOL in the Same Relation trial SCHOOL : PRINCIPAL :: SHIP: CAPTAIN was changed with the word PURCHASE to generate the Different Relation trial. We used a computer program called MATCH (Van Casteren \& Davis, 2007) to create two equivalent groups of 12 analogies (24 in total) matched on length, orthographic neighborhood size, dominance of the fourth term, semantic similarity and co-occurrence in order to avoid confounds in the within-subject conditions in our design. ANOVA revealed no significant differences between the groups on all variables. A full list of the original and the translated stimuli can be seen in Appendices 1 and 2.

Filler trials Nonword trials were trials in which at least one of the letter strings was not a word. In order to balance both the number of WORDS and NONWORDS decisions and their possible combinations, as well as to add catch WORDS decisions that were not one after the other to prevent participants from anticipating the experimental trials, we created 48 filler trials of four strings, 24 of which had a NONWORDS decision for both base and target; the other 24 were either WORDS-NONWORDS or the opposite. This resulted in 72 WORDS decisions and 72 NONWORDS decisions, including the experimental trials. Nonwords were pronounceable letter strings that were generated from real words by changing one or two letters. Thus, the base and the target were similarly related on only 12 of the 72 trials (relatedness proportion = $16.6 \%)$.

Design The only independent variable was whether the relation was shared between the base and the target, which was manipulated within-subject (Same Relation vs. Different Relation conditions). For each participant half of the target pairs were preceded by a base pair with the Same Relation, and half were preceded by a base pair with a Different Relation.

Between-subject counterbalancing While we did everything to match the groups on the most significant variables related to priming effects, we gave half of the participants one of the groups of experimental stimuli in the Same Relation condition and the other in the Different Relation condition; the groups were reversed for the other half of the participants.

Procedure The experiment was administered individually in a soundproof booth with E-Prime 2.0 software, and responses were collected via SRBOX. The participant read the instructions on a screen, and afterwards the experimenter additionally 
clarified the procedure. The experiment was double-blind. Each participant was presented with 15 training trials followed by the 72 experimental and filler trials in fully randomized order. If both letter strings were words, the participant was instructed to push the button on a serial button box marked "YES" with the index finger of his dominant hand, and if one or both were nonwords, the participant had to push "NO" with the index finger of the other hand. All analyses were done on trials in which the correct answer was "YES."

A single trial went as follows (see Fig. 1 for a detailed representation). A fixation cross appeared in the middle of the screen for $1,000 \mathrm{~ms}$, followed by two strings of letters presented at the same time one under the other, and the participant had to press one button if both strings formed words and another in all other cases. If no decision was made within $3,000 \mathrm{~ms}$, the procedure went forward automatically. A blank screen of $700 \mathrm{~ms}$ intervened between the base and the target. We chose $700 \mathrm{~ms}$ because this seems to be the minimal interval between the base and the target that is necessary for the effect to appear (Hristova, 2009a; the only difference in our study is the nature of the task - lexical decision instead of color judgments). The target was presented and responded to in the same way as the base. After the participant made a lexical decision, the next trial started.

\section{Results and discussion}

Only trials with correct answers on both the base and the target were considered (error rate $6.1 \%$ and $0.5 \%$, respectively). We excluded from the analysis RTs that were above or below 2.5 MAD, calculated separately for each participant $(7.8 \%$; absolute deviation around the median is more robust to outliers compared to standard deviations around the mean - Leys, Ley, Klein, Bernard, \& Licata, 2013). We used $R$ (R Core Team, 2014) and lme4 (Bates, Maechler, Bolker, \& Walker, 2014) to analyze the reaction times via a linear mixed effects regression with participants and items as crossed random intercept effects, which has several advantages over aggregated ANOVAs, including analyzing all data

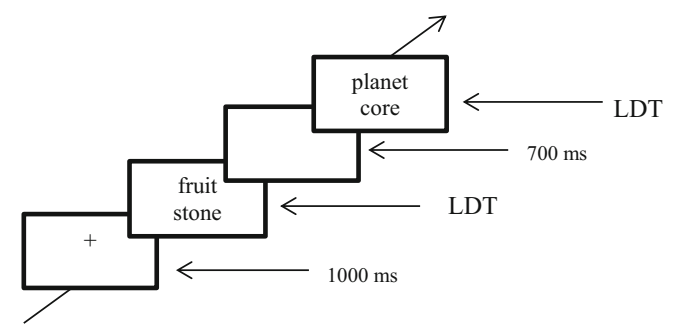

Fig. 1 Timing of events for a single trial in experiment 1 points, not only the aggregated means over subjects (bysubject analysis) or items (by-items analysis; Baayen, Davidson, \& Bates, 2008). All $p$ values were obtained by likelihood ratio tests of the model with the effect in question compared with an identical model which lacked only the effect in question (Baayen, 2008; Winter, 2013).

Main analysis of the target pair Figure 2 presents the mean RT per condition for both the base and the target pairs. A mixed linear regression model with relational condition (Same Relation vs. Different Relation) as a fixed effect yielded a significant facilitation of reaction times in the target pair in the Same Relation condition $(M=$ $946 \mathrm{~ms}, S E=8 \mathrm{~ms}$ ), compared to the Different Relation condition $(M=980 \mathrm{~ms}, S E=8 \mathrm{~ms}), \triangle A I C=-10, L L R$ $\chi^{2}(1)=11.454, p<.001,95 \%$ CI of the difference $[-54$ $\mathrm{ms},-14 \mathrm{~ms}]$. Participants recognized the target pair more quickly when it was preceded by a base pair that was relationally similar to the target.

Analyses of the base pair However, relational priming is not the only possible explanation for the facilitation. Although only one of the words in the base pair was different in the Same Relation and Different Relation conditions (FRUIT-PIT vs. STAGE-PIT), the related primes might have been easier to process than unrelated primes (e.g., due to integrative priming; Estes \& Jones, 2009). Transfer effects from the base processing speed may lead to faster or slower processing of the target, depending on the condition. To test this explanation we first ran the same mixed-effects analysis on the reaction times for the base pair. Reaction times for the base pair were faster in the Same

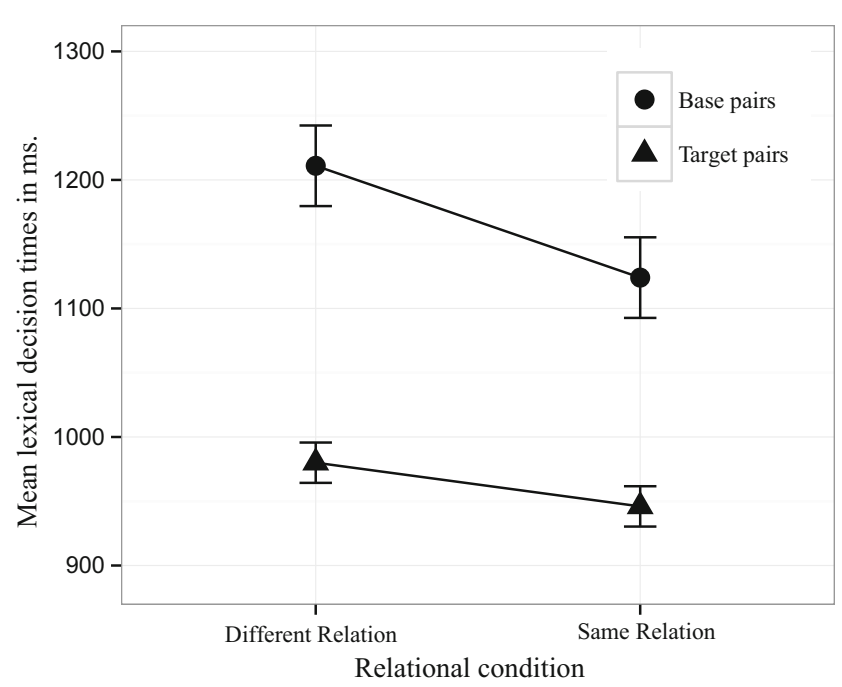

Fig. 2 Mean RTs in experiment 1 for the LDT in the base and the target pairs depending on the relational condition (Same Relation vs Different Relatio) 
Table 1 Parameters for the final mixed regression model for Experiment 1

\begin{tabular}{llcl}
\hline Fixed effects & Estimate $(S E)$ & $t$ value & Analysis** \\
\hline intercept & $881 \mathrm{~ms} \mathrm{(40)}$ & 22.250 & \\
base reaction time & $0.104 \mathrm{~ms}(0.02)$ & 5.603 & $\Delta A I C=-28, L L R \chi^{2}(1)=29.969, p<.001$ \\
presentation order & $-1.97 \mathrm{~ms}(0.77)$ & -2.553 & $\Delta A I C=-5, L L R \chi^{2}(1)=6.488, p=.011$ \\
relational condition* & $-26 \mathrm{~ms} \mathrm{(11)}$ & -2.446 & $\Delta A I C=-4, L L R \chi^{2}(1)=5.940, p=.015$ \\
\hline
\end{tabular}

Note: * The Different Relation condition was the reference category. ** All $p$ values were obtained by likelihood ratio tests of the model with the effect in question compared with an identical model that lacked only the effect in question (Baayen, 2008; Winter 2013)

Relation condition $(M=1,124 \mathrm{~ms}, S E=16 \mathrm{~ms})$, compared to Different Relation condition $(M=1,211 \mathrm{~ms}, S E=16 \mathrm{~ms})$, $\triangle A I C=-20, \operatorname{LLR} \chi^{2}(1)=21.405, p<.001,95 \%$ CI of the difference [-138 $\mathrm{ms},-43 \mathrm{~ms}$ ].

Since processing of the base cannot be affected by its relation to the target, this effect may be due to systematic differences in the related and unrelated base pairs. The word that was changed from the related to the unrelated base pair was controlled for frequency and length with the original word in the related base pair and for semantic similarity and co-occurrence with the target. However, a subsequent analysis ${ }^{4}$ revealed that the first word in the base had greater imageability in the Same Relation condition $(M=5.8, S E=0.2)$ compared to the Different Relation condition $(M=4.0, S E=0.3), t(46)=-5.71, p<$ .001 . It also had greater semantic similarity with the second word in the base in the Same Relation condition $(M=4.6, S E$ $=0.1)$ compared to the Different Relation condition $(M=1.4$, $S E=0.1), t(46)=-28.75, p<.001$, and greater co-occurrence rating with the second word in the base in the Same Relation condition $(M=0.84, S E=0.17)$ compared to the Different Relation condition $(M=0.04, S E=0.01), t(46)=-4.66, p<$ .001. A mixed-model analysis on the reaction times in the base pair with imageability, co-occurrence and semantic similarity in the base pair as fixed effects revealed that greater imageability, $\triangle A I C=-2, L L R \chi^{2}(1)=4.295, p=.038$, and greater semantic similarity led to faster reaction times, $\triangle A I C$ $=-2, L L R \chi^{2}(1)=2.8515, p=.09$; for co-occurrence $-\triangle A I C=$ 2, $\operatorname{LLR} \chi^{2}(1)=0.001, p=.992$. After accounting for imageability and semantic similarity, the relational condition had no effect on the reaction time for the base pairs, $\triangle A I C=1$, $\operatorname{LLR} \chi^{2}(1)=1.147, p=.28$.

Reanalysis of the target pair Yet, neither imageability, $\triangle A I C$ $=1, L L R \chi^{2}(1)=1.046, p=.306$, nor semantic similarity, $\triangle A I C=-1, L L R \chi^{2}(1)=2.0865, p=.18$, in the base accounted for the difference in reaction times found in the target.

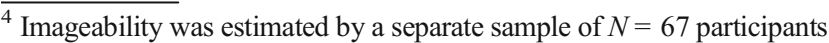
on a scale from 1 (low imagery) to 7 (high imagery) following Paivio, Yuille, and Madigan's (1968) procedure. Co-occurrence and semantic similarity was estimated for the base pairs by a separate sample of $N=$ 53 participants with the same procedure as before.
}

However, reaction times for the base pair did predict reaction times for the target, $\triangle A I C=-33, \operatorname{LLR} \chi^{2}(1)=34.943, p<$ .001. Most importantly, even when variance in the target due to reaction times for the base were taken into account, the target was still recognized faster in the Same Relation condition compared to the Different Relation condition, $\triangle A I C=-4$, $\operatorname{LLR} \chi^{2}(1)=6.118, p=.013$. Since in a regression analysis the variance explained by each variable is unique (Gelman and Hill 2006), this analysis revealed that the facilitation we found in the target was not due to systematic differences in the processing speed of the base in the Same Relation and Different Relation conditions.

Finally, to further test the unintended nature of the effect, we examined whether the facilitation was present from the beginning of the experiment or if it appeared only after participants were presented with several examples of similarly related pairs. A mixed linear regression model with relational condition, presentation order, their interaction, and reaction times for the base as fixed effects showed that although people did became faster as the experiment progressed, $\triangle A I C=-5, L L R \chi^{2}(1)=$ $6.488, p=.011$, the facilitation in the Same Relation condition remained stable throughout the experiment, $\triangle A I C=2, \operatorname{LLR} \chi^{2}(1)=0.382, p=.536$. Table 1 presents the significant parameters for the final model.

Overall, the analyses demonstrated that people made a lexical decision faster for target pairs of words that were preceded by similarly related base pairs of words, and that while the relational condition was confounded with imageability and semantic similarity within the base pair, the facilitation in the Same Relation condition remained even when variance due to processing differences in the base pair and presentation order were accounted for.

\section{Experiment 2}

In Experiment 2 we tested whether a shared relation between the base and the target would facilitate lexical decisions even in a dual-task condition where the second task taxes heavily the executive resources. We 
interfered with executive processing by using a random interval generation (RIG) task (Vandierendonck et al., 1998), where participants have to press a button in such a way that the intervals between every two presses form a random pattern. This task has several advantages over the more common random digit generation task - it loads only the executive component and not the nonexecutive verbal loop, it is easily administrable, and it has a complimentary task that is similar in all processes, but the executive one - generating fixed intervals (FIG). By comparing the two tasks, one can determine if simple physical interference is responsible for any effect. RIG has been shown to interfere with tasks that require executive resource, while the FIG does not. Thus, participants in Experiment 2 performed the LDT in three conditions - on its own (as in Experiment 1), concurrently with a RIG task, or with an FIG task.

\section{Method}

Participants Fifty-one undergraduates (33 women) at New Bulgarian University participated for partial fulfillment of course credit or volunteered to do so. All were native Bulgarian speakers whose mean age was 23.43 years $(S D=$ 3.86 ), ranging from 18 to 39 years.

Materials The stimuli were the same as in Experiment 1.

Design A 2 (relational condition: Same Relation vs. Different Relation) by 3 (type of task: single-task vs. FIG dual-task vs RIG dual-task) within-subject design was used.

Procedure Participants were tested individually on a computer using E-Prime 2.0 software. The participant read instructions on a screen, which were additionally clarified by the experimenter afterwards. The experiment was double-blind. Participants were first trained to press a foot pedal attached to the SRBOX with their dominant foot. In the FIG training they were instructed to press the foot pedal uniformly two times per second for 30 seconds. In the RIG training they were instructed to produce a random sequence of presses, that is, to press the foot pedal in such a way that the time between every two presses was a random interval of maximum two seconds. They also heard an audio recording of simple auditory signals that were spaced randomly to give them an idea how randomly generated intervals sound like. They trained the RIG task for 30 seconds. Participants were given feedback about their performance both during and after training. The main training phase concluded with training of the 15 LDT trials. The rest of the experiment was divided into three blocks. In one block participants performed only the LDT, in the second they performed the LDT simultaneously with the FIG task, and in the third the LDT simultaneously with the RIG tasks. The order of the blocks was randomized for each participant, and trials for the LDT were randomized within each block. In the dual-task conditions there was an additional training phase of 15 LDT trials in which participants trained to perform the two tasks simultaneously.

Lexical decision task The procedure for the LDT was identical to the one used in Experiment 1.

Fixed and random interval generation In the dual-task FIG condition, participants were asked to press a foot pedal at a fixed pace of two presses per second while performing the LDT at the same time. In the dual-task RIG condition, participants had to generate an unpredictable rhythm of presses, such that the time between every two presses was a random interval less than 2 seconds while performing the LDT at the same time. The difficulty of the task produced high levels of anxiety in some of the pilot participants, and it severely disrupted the main task to the point that most trials in the LDT were not performed at all. For that reason during training of the dual-task condition we told participants that most people initially find the task very difficult, so it is normal if they find it difficult as well but that it should not worry them because the training is for precisely that purpose. After the training the experimenter told them they had performed better than average. In both dual-task conditions the experimenter emphasized that both tasks are equally important and they should try to perform as fast and as correctly as possible the LDT, while at the same time try to generate a maximally random/steadily fixed rhythm of sequence of intervals.

\section{Results}

Only trials with correct answers on the base and target were considered $(10.6 \%$ and $3 \%$ error rate on base and target, respectively). We excluded from the analysis RTs that were above or below 2.5 MAD, calculated separately for each participant $(5.1 \%)$.

Analysis of the target pair Figure 3 presents the mean RT per condition. A mixed linear regression model with relational condition, type of task, and their interaction as fixed effects yielded a significant facilitation of reaction times in the target pair in the Same Relation condition $(M=980 \mathrm{~ms}, S E=10 \mathrm{~ms})$ compared to the Different Relation condition $(M=1,026 \mathrm{~ms}, S E=12$ $\mathrm{ms}), \triangle A I C=-3, \operatorname{LLR} \chi^{2}(2)=7.489, p=.023,95 \% \mathrm{CI}$ of the difference $[-70 \mathrm{~ms},-18 \mathrm{~ms}]$. There was also a significant main effect of type of task - people were fastest in the single task condition $(M=959 \mathrm{~ms}, S E=$ $14 \mathrm{~ms})$, slower in the FIG condition $(M=1,001 \mathrm{~ms}, S E$ $=14 \mathrm{~ms})$ and slowest in the RIG condition $(M=1,048$ $\mathrm{ms}, S E=16 \mathrm{~ms}), \triangle A I C=-8, L L R \chi^{2}(1)=10.803, p=$ 


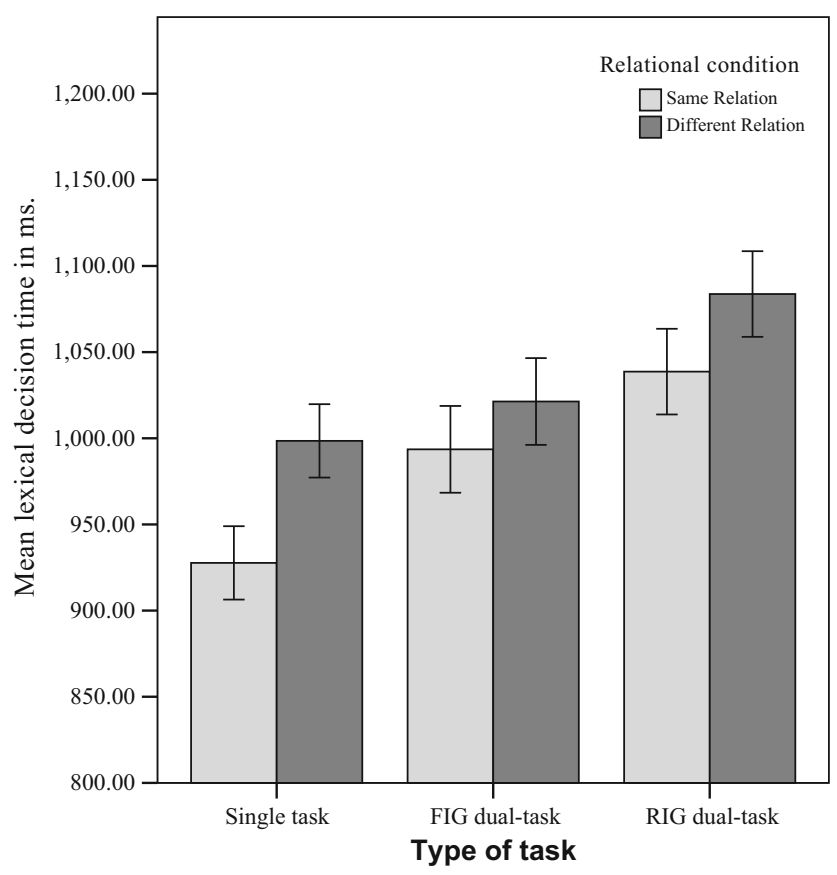

Fig. 3 Mean RTs in experiment 2 for the LDT in the target pair depending on the relational condition (Same Relation vs Different Relation) and the type of task the participant was performing

.001. Pairwise comparisons revealed that only the difference between the single task and RIG conditions reached significance, $95 \%$ CI [-158 ms, $-23 \mathrm{~ms}]$. There was no interaction between the two factors, $\triangle A I C=1$, LLR $\chi^{2}(2)=2.8074, p=.25$. Pairwise comparisons revealed that the facilitation in the Same Relation condition was present for all task conditions, although it was significantly different from zero only for the single task condition, $M=67 \mathrm{~ms}, 95 \%$ CI [32 ms, $102 \mathrm{~ms}$ ], and for the random-interval generation task condition, $M$ $=52 \mathrm{~ms}, 95 \% \mathrm{CI}[2 \mathrm{~ms}, 102 \mathrm{~ms}]$, and not significant for the fixed-interval generation task condition, $M=16$ $\mathrm{ms}, 95 \%$ CI $[-25 \mathrm{~ms}, 58 \mathrm{~ms}]$.

Analysis of the base pair As in Experiment 1, reaction times were faster for base pairs in the Same Relation condition ( $M=$ $1053 \mathrm{~ms}, S E=13 \mathrm{~ms}$ ) compared to base pairs in the Different Relation condition $(M=1198 \mathrm{~ms}, S E=16 \mathrm{~ms}), \triangle A I C=-49$, $L L R \chi^{2}(1)=50.35, p<.001$. The type of task had no effect on the base pairs, $\triangle A I C=12, L L R \chi^{2}(2)=1.757, p=.415(M=$ $1169 \mathrm{~ms}, S E=19 \mathrm{~ms} ; M=1097 \mathrm{~ms}, S E=16 \mathrm{~ms} ; M=1108$ $\mathrm{ms}, S E=18 \mathrm{~ms}$; for the single, fixed and random interval conditions respectively), and there was no interaction between the two, $\triangle A I C=10, \operatorname{LLR} \chi^{2}(2)=3.3173, p=.19$. The facilitation in lexical decision for the base pair was accounted for by the difference in semantic similarity in the related and unrelated base pairs, $\triangle A I C=-7, \operatorname{LLR} \chi^{2}(1)=14.571, p<$ .001 .
Reanalysis of the target pair Semantic similarity in the base pair was also a significant predictor of reaction times for the target pair, $\triangle A I C=-9, \operatorname{LLR} \chi^{2}(1)=10.816, p=.001$. Due to a high collinearity between the factors relational condition and semantic similarity in the base pair $(\mathrm{VIF}=27.97)$, both factors cannot be included in the same model for comparison. However, after controlling for the reaction times in the base, $\triangle A I C=-31, \operatorname{LLR} \chi^{2}(1)=33.351, p<.001$, the facilitation in the Same Relation condition in the target remained, $\triangle A I C=-2, L L R \chi^{2}(1)=3.721, p=.053$, as did the effect for type of task, $\triangle A I C=-6, \operatorname{LLR} \chi^{2}(2)=9.702$, $p=.007$, and there was no interaction between them, $\triangle A I C=2, L L R \chi^{2}(2)=1.906, p=.385$. Contrary to Experiment 1, trial order had no effect on reaction times, $\triangle A I C=2, L L R \chi^{2}(1)=0.0947, p=.758$, and there was no interaction with relational condition as well, $\triangle A I C=1, \operatorname{LLR} \chi^{2}(1)=1.054, p=.304$.

\section{General discussion}

Two experiments demonstrated that relational priming occurs efficiently and without intention. Experiment 1 showed that lexical decisions were faster for word pairs (PLANET-CORE) that were preceded by relationally similar, but semantically and associatively dissimilar word pairs (FRUIT-PIT), compared to relationally dissimilar ones (STAGE-PIT). This happened in the absence of explicit instructions to attend to the shared relations, thus demonstrating unintentional relational priming. Experiment 2 further revealed that relational priming is also efficient - it occurs even when executive resources are occupied by a taxing secondary task.

While it could be argued that the SOA we used (700 $\mathrm{ms}+$ around $1,000 \mathrm{~ms}$ for the lexical decision on the base pair) is usually indicative of controlled processing (Neely, 1991; Jones \& Estes, 2012; Mather et al., 2014), those values are valid for the much simpler forms of associative and semantic priming, where the prime is a single word, whereas for relational priming two words have to be processed and relationally integrated as well, before any priming begins. If no time is allotted for the relation that holds between them to be activated, it is not possible for it to be primed (for empirical data, see Hristova, 2009a). Furthermore, we used a low relatedness proportion $(16 \%)$, which is the probability that the base and target pairs are related during the experiment. It is usually considered that if an effect is under controlled processing, it would be harder to obtain it with low relatedness proportions, and the facilitation would be lower or nonexistent with them, compared to high relatedness proportions $(>80 \%)$ (Jones \& Estes, 2012; Mather et al., 2014; Neely, 
1991). Finally, if the effect was present because at some point the participants started to notice and use the common relations, it would have become stronger as the experiment progressed, but that was not the case. Our argument is that combined, the overall pattern that participants were not instructed about the relational similarity, the stability of the effect under dual-task demands, the low relatedness proportion, the lack of interaction with presentation order, and the use of a wide variety of relations (see Appendix 2) provides evidence that relational priming may be unintentional and efficient.

Our study extends the classical priming effect in visual word recognition (Neely, 1991) by demonstrating that it also applies to implicit relations. Some authors have challenged the commonly accepted claim that words are automatically processed to the lexical/ semantic level, because priming effects can be prevented (Besner \& Stolz, 1999; Besner, Stolz, \& Boutilier, 1997). Besner and his colleagues argue that what is usually termed automatic processing is a default mode of processing, which can be affected by task demands and context. Our results are compatible with both positions, since we make no claim whether relational priming is uncontrollable or not but that it occurs unintentionally and efficiently. A more in-depth and systematic exploration of relational priming should determine what factors affect it and in what way.

Subsequent studies on relational priming should more carefully control the characteristics of the words in the base pairs. In our stimuli, changing one word in the base pair transformed the relation between the two words (FRUIT-PIT vs. STAGEPIT), but it also decreased the semantic similarity and cooccurrence between the first and the second word in the base pair in the Different Relation condition. Also, the imageability of the new word in the base was higher compared with the substituted one. In Experiment 1, none of these differences in the base pair predicted lexical decision times for the target, but in Experiment 2, higher semantic similarity in the base pair predicted faster reaction times for the target. In both experiments, however, targets were recognized significantly faster in the Same Relation condition even when reaction times for the base had been controlled for. Thus, while the analyses show that target pairs were recognized more easily following relationally similar base pairs, and that these differences were probably not due to confounds with imageability and semantic similarity, our findings should be replicated with more carefully controlled stimuli.

If our results are replicated, it may be inferred that the cognitive system unintentionally uses relations implicitly present in the input to process subsequent stimuli. This possibly happens not only when relational integration is both necessary and advantageous (sensicality task; Estes \& Jones, 2006) but also when it is irrelevant (lexical decision task, this study), or even detrimental for performance (Stroop colornaming task; Hristova, 2009b). This might be the result of spreading activation from the activated relation to the rest of its instances, and it may be implicated in a variety of cognitive functions that require the integration and use of relational information because it makes it more salient and readily accessible. For example, during language comprehension, both object and relational information is pooled and integrated into a meaningful structure, and the priming of relations and relational structures might facilitate that process (Gagné, 2001; Estes \& Jones, 2006, 2009; Mather et al., 2014; Pickering \& Ferreira, 2008).

Relational and structural priming can also facilitate higher order relational reasoning. The depth and quality of analogical reasoning depend crucially both on the way relations are represented in the target, and on the accessibility of appropriate analogs. Relational recognition and subsequent target representation is often taken for granted by most computational models of analogy making (for a review, see Gentner \& Forbus, 2011), but relations are only implicitly present in the environment - they have to be elicited out of the continuous multimodal informational stream, and, furthermore, they have to be recognized among the numerous potential relations that hold between objects (Doumas, Hummel, \& Sandhofer, 2008; French, 2008; Hristova, 2009a; Vankov \& Kokinov, 2009). One mechanism that facilitates the recognition of relations is comparison, which highlights the common relational structure and allows its recognition (Gentner, 2010). Another can certainly be relational priming - relational and structural priming may make relations more salient, and they can facilitate the recognition not only of trivial and mundane relations but that of nontypical and creative ones as well (Hristova, 2009a, Experiment 1). Finally, relational priming offers a way to circumvent the difficulty of relational retrieval, which is the other major obstacle in the path of spontaneous analogies (Gentner, 2010; Holyoak, 2012), by making appropriate analogs more easily accessible.

This is a fruitful area for future research, and while we disagree with Holyoak (2012) that all implicit analogical reasoning is simply the result of relational priming, we agree with his assessment that it will be increasingly important to understand how these types of relational processing relate to one another.

Author's note We would like to acknowledge the help and guidance we received from Boicho Kokinov. In many ways he determined the way this research now looks. We would like to thank Georgi Petkov and Hristo Hristov for their continuous support and stimulating discussions, and Polina Petrova, Mila Smilyanova, Lora Kuzmanova, Maria Mazneva and Boyan Drenski for their help in collecting the data. We are grateful to Ivan Vankov and the anonymous reviewers for taking the time to review our work and for their helpful comments and suggestions. 


\section{Appendices}

\section{Appendix 1}

Table 2 Original stimuli in Bulgarian

\begin{tabular}{|c|c|c|}
\hline Unrelated base & Related base & Target \\
\hline цел - килим & под - килим & маса - покривка \\
\hline заем - мебел & стол - мебел & вилица - прибор \\
\hline етап - костилка & плод - костилка & планета - ядро \\
\hline бележка - пилот & самолет - пилот & кон - ездач \\
\hline магазин - художник & картина - художник & статуя - скулптор \\
\hline терор - бетон & панел - бетон & прозорец - стъкло \\
\hline тема - лапа & куче - лапа & магаре - копито \\
\hline паника - залез & изгрев - залез & раждане - смърт \\
\hline хор - часовник & час - часовник & месец - календар \\
\hline котва - трева & поляна - трева & плаж - пясък \\
\hline начин - крака & човек - крака & дърво - корени \\
\hline покупка - директор & училище - директор & кораб - капитан \\
\hline възраст - летище & самолет - летище & кораб - пристанище \\
\hline заглавие - четка & художник - четка & шивач - игла \\
\hline власт - къща & човек - къща & птица - гнездо \\
\hline глупост - ват & мощност - ват & температура - градус \\
\hline стъкленица - инструкция & сглобяване - инструкция & готвене - рецепта \\
\hline упойка - съдове & миялна - съдове & пералня - дрехи \\
\hline залог - хол & диван - хол & фурна - кухня \\
\hline название - паство & свещеник - паство & овчар - стадо \\
\hline наемател - астрономия & телескоп - астрономия & микроскоп - биология \\
\hline врьх - болка & удар - болка & шега - смях \\
\hline традиция - семе & растение - семе & риба - хайвер \\
\hline паметник - парола & компютьр - парола & катинар - ключ \\
\hline
\end{tabular}

\section{Appendix 2}

Table 3 Translated stimuli ${ }^{\mathrm{a}}$

\begin{tabular}{llll}
\hline Unrelated base & Related base & Target & Relation \\
\hline aim - carpet & floor - carpet & table - tablecloth & is covered with \\
chair - furniture & fork - cutlery & planet - core & is a kind of \\
stage - pit & fruit - pit & horse - rider & is in the center of \\
note - pilot & airplane - pilot & is driven by \\
store - painter & painting - painter & statue - sculptor & is created by \\
terror - concrete & panel - concrete & window - glass & is made of \\
topic - pow & dog - pow & donkey - hoof & is a part of \\
panic - sunset & sunrise - sunset & birth - death & parts of a cycle \\
choir - watch & hour - watch & month - calendar & is measured by \\
anchor - grass & meadow - grass & beach - sand & is made of \\
method - legs & human - legs & tree - roots & is a part of \\
purchase - principal & school - principal & ship - captain & is driven/lead by
\end{tabular}


Table 3 (continued)

\begin{tabular}{|c|c|c|c|}
\hline Unrelated base & Related base & Target & Relation \\
\hline age - airport & airplane - airport & ship - shipyard & is housed at \\
\hline title - brush & artist - brush & tailor - needle & is an instrument of \\
\hline power - house & person - house & bird - nest & lives in \\
\hline stupidity - watt & power - watt & temperature - degree & is measured in \\
\hline flask - instructions & construction - instructions & cooking - recipe & is achieved following \\
\hline anaesthetic - dishes & dishwasher - dishes & washing-machine ${ }^{\mathrm{d}}$ - clothes & is used for \\
\hline bet - living room & couch - living room ${ }^{\mathrm{e}}$ & oven - kitchen & is situated in \\
\hline name - congregation & priest - congregation & shepherd - flock & is the leader of \\
\hline tenant - astronomy & telescope - astronomy & microscope - biology & is used in \\
\hline peak - pain & hit - pain & joke - laughter & causes \\
\hline tradition - seed & plant - seed & fish - caviar & is grown from \\
\hline monument - password & computer - password & padlock - key & is unlocked by \\
\hline
\end{tabular}

Translation notes:

${ }^{a}$ In the original Bulgarian stimuli, no words within the base and the target had the same root

b In Bulgarian, two nouns generally cannot be understood as a phrase, as in English - while in English it makes sense to say "An airplane pilot" to mean a pilot who drives an airplane, in Bulgarian it does not

c In Bulgarian, "dishwasher" and "washing-machine” are not compound nouns and are not morphologically related

d "Living room" is a single word in Bulgarian

5. In Bulgarian, the first words in the unrelated and related bases have the same length and frequency

\section{References}

Baayen, R. (2008). Analyzing linguistic data: A practical introduction to statistics using $R$. Cambridge, England: Cambridge University Press.

Baayen, R. H., Davidson, D. J., \& Bates, D. M. (2008). Mixed-effects modeling with crossed random effects for subjects and items. Journal of Memory and Language, 59(4), 390-412.

Bargh, J. A. (1994). The four horsemen of automaticity: Intention, awareness, efficiency, and control as separate issues. Handbook of Social Cognition, 1, 1-40.

Bassok, M., Pedigo, S. F., \& Oskarsson, A. T. (2008). Priming addition facts with semantic relations. Journal of Experimental Psychology: Learning, Memory, and Cognition, 34(2), 343.

Bates D., Maechler, M., Bolker, B., \& Walker, S. (2014). Ime4: Linear mixed-effects models using Eigen and S4 (R package version 1.17). Retrieved from http://CRAN.R-project.org/package=lme4

Bendig, B. W., \& Holyoak, K. J. (2009). Relational priming of analogical reasoning. In B. Kokinov, K. Holyoak \& D. Gentner (Eds.), New Frontiers in analogy research: Proceedings of the second international conference on analogy (pp. 30-36). Sofia, Bulgaria: NBU press

Besner, D., \& Stolz, J. (1999). Context dependency in Stroop's paradigm: When are words treated as nonlinguistic objects? Canadian Journal of Experimental Psychology/Revue Canadienne de Psychologie, 53(4), 374.

Besner, D., Stolz, J. A., \& Boutilier, C. (1997). The Stroop effect and the myth of automaticity. Psychonomic Bulletin \& Review, 4(2), 221225.

Blanchette, I., \& Dunbar, K. (2002). Representational change and analogy: How analogical inferences alter target representations. Journal of Experimental Psychology: Learning, Memory, and Cognition, $28(4), 672$.
Chaffin, R., \& Herrmann, D. J. (1984). The similarity and diversity of semantic relations. Memory \& Cognition, 12(2), 134-141.

Chaffin, R., \& Herrmann, D. J. (1988). Effects of relation similarity on part-whole decisions. Journal of General Psychology, 115(2), 131.

Day, S. B., \& Gentner, D. (2007). Nonintentional analogical inference in text comprehension. Memory \& Cognition, 35(1), 39-49. doi:10. 3758/BF03195940

Day, S., \& Goldstone, R. (2011). Analogical transfer from a simulated physical system. Journal of Experimental Psychology: Learning, Memory, and Cognition, 37, 551-567.

Dixon, J., \& Dohn, M. (2003). Redescription disembeds relations: Evidence from relational transfer and use in problem solving. Memory \& Cognition, 31(7), 1082-1093.

Doumas, L. A., Hummel, J. E., \& Sandhofer, C. M. (2008). A theory of the discovery and predication of relational concepts. Psychological Review, 115(1), 1.

Estes, Z. (2003). Attributive and relational processes in nominal combination. Journal of Memory and Language, 48(2), 304-319. doi:10. 1016/S0749-596X(02)00507-7

Estes, Z., \& Jones, L. L. (2006). Priming via relational similarity: A copper horse is faster when seen through a glass eye. Journal of Memory and Language, 55(1), 89-101.

Estes, Z., \& Jones, L. L. (2009). Integrative priming occurs rapidly and uncontrollably during lexical processing. Journal of Experimental Psychology: General, 138(1), 112-130.

Eysenck, M. W., Derakshan, N., Santos, R., \& Calvo, M. G. (2007). Anxiety and cognitive performance: Attentional control theory. Emotion, 7(2), 336-353.

Fisher, K. J., Bassok, M., \& Osterhout, L. (2010). When two plus two does not equal four: Event-related potential responses to incongruous arithmetic word problems. In S. Ohlsson \& R. Catrambone (Eds.), Proceedings of the 32nd Annual Conference of the Cognitive Science Society (pp. 1571-1576). Austin, TX: Cognitive Science Society. 
French, R. M. (2008). Relational priming is to analogy-making as oneball juggling is to seven-ball juggling. Behavioral and Brain Sciences, 31(04), 386-387.

Gagné, C. L. (2001). Relation and lexical priming during the interpretation of noun-noun combinations. Journal of Experimental Psychology: Learning, Memory, and Cognition, 27(1), 236.

Gagné, C. L. (2002). Lexical and relational influences on the processing of novel compounds. Brain and Language, 81, 723-735.

Gelman, A., \& Hill, J. (2006). Data analysis using regression and multilevel/hierarchical models. Cambridge, England: Cambridge University Press.

Gentner, D. (2010). Bootstrapping the mind: Analogical processes and symbol systems. Cognitive Science, 34(5), 752-775.

Gentner, D., \& Forbus, K. D. (2011). Computational models of analogy. Wiley Interdisciplinary Reviews: Cognitive Science, 2(3), 266-276.

Gentner, D., \& Smith, L. (2012). Analogical reasoning. In V. S. Ramachandran (Ed.), Encyclopedia of human behavior (2nd Ed., 130-136). Oxford, UK: Elsevier.

Green, A., Fugelsang, J., \& Dunbar, K. (2006). Automatic activation of categorical and abstract analogical relations in analogical reasoning. Memory \& Cognition, 34, 1414-1421.

Hofstadter, D. (1979). Godel, Escher, Bach: An eternal golden braid. New York, NY: Basic Books.

Hofstadter, D. (1984). The Copycat project: An experiment in nondeterminism and creative analogies. MIT AI Memo, 755

Hofstadter, D. (2001). Analogy as the core of cognition. In D. Gentner, K. Holyoak, \& B. Kokinov (Eds.), The analogical mind: Perspectives from cognitive science (pp. 499-538.). Cambridge, MA: The MIT Press/Bradford Books.

Hofstadter, D., \& Sander, E. (2013). Surfaces and essences: Analogy as the fuel and fire of thinking. New York, NY: Basic Books.

Holyoak, K. J. (2012). Analogy and relational reasoning. In K. J. Holyoak \& R. G. Morrison (Eds.), The Oxford handbook of thinking and reasoning (pp. 234-259). Oxford, England: Oxford University Press.

Hristova, P. (2009a). Unconscious analogical mapping? In N. A. Taatgen \& H. van Rijn (Eds.), Proceedings of the 31th Annual Conference of the Cognitive Science Society (pp. 655-660). Austin, TX: Cognitive Science Society.

Hristova, P. (2009). Unintentional and unconscious analogies between superficially dissimilar but relationally similar simple structures. In B. Kokinov, K. Holyoak \& D. Gentner (Eds.), New frontiers in analogy research: Proceedings of the second international conference on analogy (pp. 193-203). Sofia, BG: NBU press.

Hristova, P., \& Kokinov, B. (2011). Anxiety fosters relational encoding. In B. Kokinov, A. Karmiloff-Smith, \& N. Nersessian (Eds.), European Perspectives on Cognitive Science. Sofia, Bulgaria: NBU Press.

Hristova, P., Petkova, Y., Kokinov, B. (2013). Anxiety can influence analogy-making both positively and negatively depending on the complexity of the mapping task (pp. 627-632). In M. Knauff, M. Pauen, N. Sebanz, \& I. Wachsmuth (Eds.), Proceedings of the 35th Annual Conference of the Cognitive Science Society. Austin, TX: Cognitive Science Society.

Jones, L. L., \& Estes, Z. (2012). Lexical priming: Associative, semantic, and thematic influences on word recognition. Visual Word Recognition, 2, 44-72.

Koeva, S., Stoyanova, I., Leseva, S., Dimitrova, T., Dekova, R., \& Tarpomanova, E. (2012). The Bulgarian National Corpus: Theory and practice in corpus design. Journal of Language Modelling, O(1), $65-110$.
Leys, C., Ley, C., Klein, O., Bernard, P., \& Licata, L. (2013). Detecting outliers: Do not use standard deviation around the mean, use absolute deviation around the median. Journal of Experimental Social Psychology, 49(4), 764-766. doi:10.1016/j.jesp.2013.03.013

Mather, E., Jones, L. L., \& Estes, Z. (2014). Priming by relational integration in perceptual identification and Stroop colour naming. Journal of Memory and Language, 71(1), 57-70.

Moors, A., \& De Houwer, J. (2006). Automaticity: A theoretical and conceptual analysis. Psychological Bulletin, 132(2), 297.

Neely, J. H. (1991). Semantic priming effects in visual word recognition: A selective review of current findings and theories. In D. Besner \& G. W. Humphreys (Eds.), Basic processes in reading: Visual word recognition (pp. 264-336). Hillsdale, NJ: Erlbaum.

Paivio, A., Yuille, J. C., \& Madigan, S. A. (1968). Concreteness, imagery, and meaningfulness values for 925 nouns. Journal of Experimental Psychology, 76(1, Pt. 2), 1.

Perrott, D. A., Genter, D., \& Bodenhausen, G. V. (2005). Resistance is futile: The unwitting insertion of analogical inferences in memory. Psychonomic Bulletin \& Review, 12(4), 696-702.

Pickering, M. J., \& Ferreira, V. S. (2008). Structural priming: A critical review. Psychological Bulletin, 134(3), 427-459. doi:10.1037/ 0033-2909.134.3.427

Popov, V., \& Hristova, P. (2014). Automatic analogical reasoning underlies structural priming in comprehension of ambiguous sentences. In P. Bello, M. Guarini, M. McShane, \& B. Scassellati (Eds.), Proceedings of the 36th Annual Conference of the Cognitive Science Society (pp. 1192-1197). Austin, TX: Cognitive Science Society.

R Core Team. (2014). R: A language and environment for statistical computing. Vienna, Austria: R Foundation for Statistical Computing. Retrieved from http://www.R-project.org/

Raffray, C. N., Pickering, M. J., \& Branigan, H. P. (2007). Priming the interpretation of noun-noun combinations. Journal of Memory and Language, 57(3), 380-395.

Spellman, B. A., Holyoak, K. J., \& Morrison, R. G. (2001). Analogical priming via semantic relations. Memory \& Cognition, 29(3), 383393. doi:10.3758/BF03196389

Spence, D., \& Owens, K. (1990). Lexical co-occurrence and association strength. Journal of Psycholinguistic Research, 19(5), 317-330.

Tohill, J. M., \& Holyoak, K. J. (2000). The impact of anxiety on analogical reasoning. Thinking \& Reasoning, 6(1), 27-40.

Van Casteren, M., \& Davis, M. (2007). Match: A program to assist in matching the conditions of factorial experiments. Behavior Research Methods, 39(4), 973-978.

Vandierendonck, A., De Vooght, G., \& Van der Goten, K. (1998). Does random time interval generation interfere with working memory executive functions? European Journal of Cognitive Psychology, 10(4), 413-442. doi:10.1080/713752284

Vankov, I., \& Kokinov, B. (2009). Grounding relations in action. In B. Kokinov, K. Holyoak \& D. Gentner (Eds.), New Frontiers in Analogy Research: Proceedings of the second international conference on analogy (pp. 463-472). Sofia, BG: NBU press

Waltz, J. A., Lau, A., Grewal, S. K., \& Holyoak, K. J. (2000). The role of working memory in analogical mapping. Memory \& Cognition, 28(7), 1205-1212.

Winter, B. (2013). Linear models and linear mixed effects models in $R$ with linguistic applications Retrieved from http://arxiv.org/pdf/ 1308.5499.pdf

Wisniewski, E. J., \& Love, B. C. (1998). Relations versus properties in conceptual combination. Journal of Memory and Language, 38(2), 177-202. 